\title{
O ENSINO DA XILOGRAVURA EM ESPAÇOS FORMAIS DE EDUCAÇÃO: UM INCENTIVO HISTÓRICO, ARTÍSTICO E CULTURAL
}

\author{
Fernanda Silvestre Grabner ${ }^{1}$ \\ Ana Enedi Prince ${ }^{2}$
}

Resumo: O presente artigo relata sobre a importância da aplicação de recursos didáticos e metodológicos no Ensino de história, fazendo o uso da contextualização e interdisciplinaridade por intermédio de uma oficina. Será abordada a importância do ensino da xilogravura nos espaços formais de educação presentes na cidade de Campos do Jordão, considerando a falta de incentivo histórico, artístico e cultural inexistente nesses locais. O projeto tem o intuito de mediar aos alunos uma assimilação e compreensão profunda sobre a história que circula a técnica xilográfica, contextualizando o tema e utilizando a interdisciplinaridade para alcançar tais objetivos.

Palavras-chave: Recursos didáticos e metodológicos, ensino de história, oficina xilográfica.

\footnotetext{
1 Universidade do Vale do Paraíba, Brasil. E-mail: grabnerfernanda@gmail.com.

2 Universidade do Vale do Paraíba, Brasil. E-mail: prince@univap.br.
} 